\title{
A new weight-reducing drug with novel properties
}

\author{
David Wheatley \\ M.D., F.R.C.Psych.
}

The General Practitioner Research Group, 325 Staines Road, Twickenham, U.K.

\begin{abstract}
Summary
Ciclazindol, a tetracyclic compound originally developed as an antidepressant, was compared to placebo in a double-blind trial involving 114 individuals who were at least $15 \%$ overweight. Following a one week control period patients were allocated to active or placebo groups by random distribution for a period of 4 weeks and this was followed by a final one-week observation period.
\end{abstract}

The mean weight loss of 47 patients who completed the trial on ciclazindol was $6.95 \mathrm{lbs}(3.13 \mathrm{~kg})$ and of 48 patients who completed the trial on placebo it was $5.0 \mathrm{lbs}(2.25 \mathrm{~kg})$ a difference which is statistically significant in favour of ciclazindol $(P<0.05)$.

The trial demonstrated a marked placebo effect resulting in loss of weight in these patients, but the drug effect was significantly greater.

\section{Introduction}

Ciclazindol, a tetracyclic compound, was originally developed as an antidepressant (Ghose et al., 1978; Levine, 1979). Ghose et al. (1978) in a comparative trial against amitriptyline in depression, found that over a 6-week period, patients on ciclazindol experienced a mean weight loss of $1.3 \mathrm{~kg}$, whereas those on amitriptyline experienced a mean weight gain of $0.98 \mathrm{~kg}$. Ciclazindol is a member of the pyrimido $1,2 \alpha$-indol group of drugs and has a chemical resemblance to mazindol, a compound with established weight-reducing properties (General Practitioner Research Group 1978). Mazindol increases glucose uptake into human isolated skeletal muscle (Kirby \& Turner, 1976) as does fenfluramine, another well established weight-reducing drug (Kirby, 1974) in contrast to amphetamine which has no such effect (Kirby and Turner, 1974). Kirby and Turner (1977) have shown that ciclazindol, like mazindol, produces a significant concentrationdependent increase in glucose uptake into human skeletal muscle. This may indicate a metabolic mechanism underlying the weight loss in addition to appetite suppression.

In a single blind study, Greenbaum and Harry
(1980) compared ciclazindol to placebo over a 3week treatment period following a 2-week control period. During treatment, patients on ciclazindol lost significantly more weight than those on placebo, but this was not maintained during the third week of the trial.

\section{Method}

Ciclazindol, in a dose of $25-50 \mathrm{mg}$ daily, was compared to placebo under double-blind conditions, patients being treated for 4 weeks with one or the other according to random selection, following a one-week control period with no treatment. There was also a final one-week follow-up, again with no treatment. The trial was confined to patients aged 18-65 years who were at least $15 \%$ overweight at the start of the trial, according to standard tables relating height, weight and frame for men and women (Metropolitan Life Association, 1966). By this method, frame is classified as: slight, medium or large. If weight fluctuated during the pre-study week by more than $5 \mathrm{lb}(2.25 \mathrm{~kg})$ either way, then the patient was excluded from the trial. Patients were given general instructions concerning diet, i.e.types of food to eat and suggestions about reducing amounts.

Patients were weighed without shoes or outdoor clothes at the same time on each occasion at the end of the control week, the end of each trial week and the end of follow-up week. Blood pressure and pulse rate were measured at the same intervals, after the patient had rested in the recumbent position for 3 min.

The trial was a multi-centre study undertaken by 18 general practitioners who treated a total of 114 patients, and on breaking the code it was found that 58 of these had received ciclazindol and 56 placebo. However, 11 patients in the ciclazindol group and 8 in the placebo group failed to complete the trial and so the analysis is concerned with the remaining 47 patients treated with ciclazindol and 48 with placebo. The pertinent patient data are summarized in Table 1 which shows that the two treatment groups were well matched in relation to these various items. 


\section{Results}

The mean weight-loss for all patients was calculated at each period of the trial and is presented in Fig. 1.

The data were found to be unimodally distributed with no significant difference between the initial means ( $t$-test) and were then analysed using a twoway analysis of variance, the least significant difference $(P=0.05)$ method being used to test for significant differences at the $5 \%$ level.

TABLE 1. Patient data recorded in the two treatment groups ( \pm s.e.m.). *one unknown

\begin{tabular}{|c|c|c|}
\hline & Ciclazindol & Placebo \\
\hline $\begin{array}{l}\mathbf{N} \\
\mathbf{M}: \mathbf{F} \\
\text { Mean age (years) } \\
( \pm \text { s.e.m.) }\end{array}$ & $\begin{array}{c}47 \\
5: 41^{*} \\
47 \cdot 7( \pm 1 \cdot 56)^{*}\end{array}$ & $\begin{array}{c}48 \\
4: 44 \\
44 \cdot 4( \pm 1 \cdot 91)\end{array}$ \\
\hline $\begin{array}{l}\text { Mean height (in) } \\
( \pm \text { s.e.m.) }\end{array}$ & $63.8( \pm 0.42)$ & $64.0( \pm 0.41)$ \\
\hline $\begin{array}{l}\text { Mean weight (lb) } \\
( \pm \text { s.e.m.) } \\
\text { Frame }\end{array}$ & $177 \cdot 8( \pm 4 \cdot 0)$ & $180 \cdot 5( \pm 4 \cdot 4)$ \\
\hline $\begin{array}{l}\text { Small/medium/ } \\
\text { large }\end{array}$ & $7 / 28 / 12$ & $10 / 23 / 14^{*}$ \\
\hline
\end{tabular}

In the ciclazindol group the mean weight was significantly less at the end of week one as compared to the end of the control week, and there was a further significant weight loss by the end of week 2 . Thereafter, there were no further significant differences at weeks 3 and 4 or the follow-up week. In the placebo group the mean weight at the end of week one was significantly less than that at the end of the control week, but the only other significant difference was between weeks 3 and 4 .

The mean weight losses were then used to compare the results between the two treatment groups and these are shown in Table 2.

In this comparison the mean weight loss was greater with ciclazindol at all periods of the trial and the drug-placebo differences achieved statistical significance at weeks 3 and 4 .

The data on weight and weight loss were analysed in similar manner within each frame size and, of the patients with a small or medium frame, those on ciclazindol lost more weight than those on placebo. This difference was statistically significant in week 3 $(P<0.05, t$-test $)$. In the group of patients with large frames, however, the weight loss was very similar for active and placebo compounds.

With both compounds there were significant reductions in mean systolic and diastolic blood pressure but not in mean pulse rate by the end of the trial. There were no significant between-group differences.

\section{Side effects}

Side effects were spontaneously volunteered and



FIG. 1. Mean weight loss ( \pm s.e.m.) of patients treated wit placebo and ciclazindol. $\mathbf{C}=$ end of control week; $\mathbf{F}=$ end of final no treatment week. -placebo. $\square$-ciclazindol.

attributed to the medications by 22 patients in the ciclazindol group $(38 \%$ of those entering the trial and by 13 in the placebo group ( $23 \%$ of those entering the trial), a difference which is not statistically significant $\left(\chi^{2}\right)$.

With the active drug the most frequent side effects were: gastric upset $(14 \%$, placebo $2 \%)$; tiredness $(10 \%$, placebo $7 \%)$; and dry mouth $(12 \%$, placebo $5 \%$ ). In the ciclazindol group, 6 patients had to stop treatment because of side effects $(10 \%)$ compared with 3 patients $(2 \%)$ in the placebo group.

TABLE 2. Cumulative weight loss during the trial. Mean figures (lb) with standard deviations (s.d.)

\begin{tabular}{lccc}
\hline Week & Ciclazindol & Placebo & Significance \\
\hline 1 & $2 \cdot 7$ & $2 \cdot 3$ & n.s. \\
2 & $(2.3)$ & $(2 \cdot 5)$ & \\
& $4 \cdot 7$ & $3 \cdot 8$ & n.s. \\
3 & $(3 \cdot 7)$ & $(3 \cdot 9)$ & \\
& $6 \cdot 2$ & $3 \cdot 9$ & $P<0.01$ \\
4 & $(4 \cdot 0)$ & $(3 \cdot 6)$ & \\
& 6.95 & $5 \cdot 0$ & $P<0.05$ \\
Follow-up & $(4.6)$ & $(4.4)$ & \\
& 6.94 & $5 \cdot 6$ & n.s. \\
& $(5 \cdot 0)$ & $(4.9)$ & \\
\hline
\end{tabular}




\section{Discussion}

The treatment of obesity is very much a problem for the general practitioner and the subject has been comprehensively reviewed by Craddock (1973, 1977). As he comments: 'Most drugs in controlled trials produce a substantially greater weight loss initially than the placebo . . . in most patients, however, the anorectic effect wears off after (2-3 months)'. The results of the short-term trial reported are, therefore, in keeping with the first part of Craddock's comment.

That food intake, energy requirement and body weight are not intimately co-ordinated has been demonstrated by Durnin (1961) and Edholm et al. (1970), in individuals of all ages and in army recruits respectively. The role of thermogenesis in the maintenance of body weight may provide the explanation, and slim individuals may be more adept at burning off extra food energy as heat. Evidence supporting this theory has been provided by Rothwell and Stock (1979) from their studies on overfed rats. In spite of consuming $80 \%$ more energy, the weight gain of these overfed rats was only $27 \%$ greater than that of the controls. They demonstrated a sustained increase in diet-induced thermogenesis and related this to changes in brown adipose tissue.

A drug which would influence fundamental metabolic processes would therefore be of particular interest from the clinical point of view in treating obese patients. Ciclazindol would appear to be a generally well tolerated drug without any marked potentiality for inducing adverse effects and so could prove a useful addition to the treatment of obesity, when drugs are required. Its long-term effectiveness must await further trials conducted over a number of months.

\section{Acknowledgments}

I would like to thank the following members of the General Practitioner Research Group who took part in this trial: C.I. Backhouse, H.P. Berg, G.R. Caird, M. Gringras, D.J. Hosie, R. Lal, A. Latham, P.I. Miller, N.E. Nathanson, B.A.W. Perkins, A.J. Pinkerton, N.M. Robertson, R.H. Soper, J.C.
Valle-Jones, T.M. Warren, F.O. Wells, and B.J. Williams. I would like to thank Jackie Turner for undertaking the statistical analysis in this trial.

\section{References}

Craddock, D. (1973) Obesity and its Management. Churchill Livingstone, Edinburgh and London.

Craddock, D. (1977) Treatment of obesity. Journal of Pharmacotherapy, 1, 43.

DURNIN, J.V.G.A. (1961) Appetite and the relationship between expenditure and intake of calories in man. Journal of Physiology, 156, 294.

Edholm, O.G., Adam, J.M., Healy, M.J.R., Wol.fF, H.S., Goldsmith, R. \& Best, T.W. (1970). Food intake and energy expenditure of army recruits. British Journal of Nutrition, 24, 1091.

General Practitioner Research Group (1978) Comparative merits of two weight reducing drugs. Journal of Pharmacotherapy, 1, 2, 35.

Ghose, K., Rama, V.A., Bailey, J. \& Coppen, A. (1978) Antidepressant activity and pharmacological interactions of ciclazindol. Psychopharmacology, 57, 109.

Greenbaum, R. \& HaRRY, T.V.A. (1980) Ciclazindol: an adjunct to weight control. Journal of Pharmacotherapy, 3, $2,82$.

KIRBY, M.J. (1974) Dose-related effect of fenfluramine and norfenfluramine on glucose uptake into human isolated skeletal muscle. British Journal of Clinical Pharmacology, 1, 511.

Kirby, M.J. \& TuRner, P. (1974) Effect of amphetamine, fenfluramine and norfenfluramine on glucose uptake into human isolated skeletal muscle. British Journal of Clinical Pharmacology, 1, 340P.

Kirby, M.J. \& TuRner, P. (1976) Effect of some receptor antagonists on fenfluramine-induced glucose uptake into the isolated rat hemidiaphragm. British Journal of Pharmacology and Chemotherapy, 58, 286P.

KIRBY, M.J. \& TURNER, P. (1977) Ciclazindol and mazindol on glucose uptake into human isolated skeletal muscle: no interaction of mazindol with methysergide. British Journal of Clinical Pharmacology, 4, 459.

LEVINE, S. (1979) A controlled comparative trial of a new antidepressant ciclazindol. Journal of International Medical Research, 7, 1.

Metropolitan Life Association (1966) Statistical Bulletin 47, (1).

Rothwell, W.J. \& Stock, M.J. (1979) A role for brown adipose tissue in diet-induced thermogenesis. Nature, 281, 31 . 